\title{
COMPREENSÃO LEITORA DE ALUNOS DO ENSINO FUNDAMENTAL II: UM ESTUDO SOBRE DESEMPENHOS, UTILIZANDO DIFERENTES TIPOS DE TAREFAS E CATEGORIAS INFERENCIAIS
}

\author{
Vera Wannmacher PEREIRA* \\ Danielle BARETTA** \\ Caroline Bernardes BORGES ${ }^{* * *}$
}

- RESUMO: Essa pesquisa teve como objetivo examinar a compreensão leitora de alunos do Ensino Fundamental II em suas relações com o nível de escolaridade e as tarefas propostas. Os sujeitos da pesquisa foram 62 alunos do $6^{\circ}$ ao $8^{\circ}$ ano do Ensino Fundamental II, de uma escola pública da cidade de Porto Alegre (RS/Brasil). A coleta de dados foi realizada utilizando Questionário, Verdadeiro ou Falso e Múltipla Escolha, com correspondência das questões entre os conteúdos e as categorias inferenciais, e Cloze. Cada sujeito respondeu a uma tarefa apenas, sendo essa distribuição realizada aleatoriamente em cada turma de alunos. Os dados coletados foram organizados e tratados estatisticamente, possibilitando a obtenção dos seguintes resultados: com relação ao nível de escolaridade, diferença significativa no desempenho em compreensão leitora $(\mathrm{p}=0,007)$, indicando progressão dos escores à medida do avanço da escolaridade; com relação ao tipo de tarefa, diferença significativa $(\mathrm{p}=0,003)$, com a tarefa de Múltipla Escolha apresentando a maior média $(4,43)$, a tarefa de Verdadeiro ou Falso a menor média $(2,60)$ e as tarefas de Questionário e Cloze médias intermediárias (3,29 e 3,28, respectivamente); com relação à categoria inferencial, evolução da capacidade de realizar inferências com o aumento do nível de escolaridade.

- PALAVRAS-CHAVE: compreensão leitora; categoria inferencial das questões; ensino fundamental.

\section{Introdução}

Provas oficiais de âmbito nacional e estadual vêm evidenciando as condições não satisfatórias dos estudantes do Ensino Fundamental no que se refere à Língua

Pontifícia Universidade Católica do Rio Grande do Sul (PUCRS), Porto Alegre - RS - Brasil. vpereira@pucrs.br. ORCID: 0000-0002-2511-6814

** Pontifícia Universidade Católica do Rio Grande do Sul (PUCRS), Porto Alegre - RS - Brasil. daniellebaretta@ hotmail.com. ORCID: 0000-0003-2679-7671

**** Pontifícia Universidade Católica do Rio Grande do Sul (PUCRS), Porto Alegre - RS - Brasil. caroline.borges93@ edu.pucrs.br. ORCID: 0000-0001-8815-9195 
Portuguesa e à Matemática, gerando preocupações sociais e acadêmicas. Conforme os resultados do SAEB 2017, em Língua Portuguesa e Matemática, nos anos iniciais, não diferente dos anteriores, 5,94 é a média padronizada das escolas públicas, com pouco acréscimo em relação a $2015(5,74)$. Em 2017, nos anos finais, a pontuação de Língua Portuguesa foi 253,74, superando pouco o resultado de 2015 (247,33). Em relação à média padronizada de Língua Portuguesa e Matemática, o resultado de 2017 $(5,09)$ apresentou uma evolução muito pequena em relação a $2015(4,97)$. O IDEB 2017, nas escolas públicas, nos anos iniciais foi 5,5 e, nos anos finais, 4,4. Em 2015, nesse mesmo âmbito, o resultado foi de 5,3 nos anos iniciais, e 4,2 nos anos finais, indicando um crescimento muito discreto. As preocupações com a situação se justificam, considerando os desempenhos em si e suas repercussões no acesso ao conhecimento dos demais campos, na evolução da escolaridade e na inserção social.

A observação desses dados e dessas informações indica todas as séries como de potenciais necessidades. A escolha aqui, entretanto, é pelos $6^{\circ}, 7^{\circ}$ e $8^{\circ}$ anos do Ensino Fundamental II, dando continuidade a um processo de compreensão iniciado e preparando o atendimento às expectativas de compreensão mais complexa nos anos seguintes.

Nesse quadro, o artigo aqui apresentado tem como tema a compreensão leitora na escola, na perspectiva da Psicolinguística, com privilégio para a perspectiva inferencial das questões (GIASSON, 2000; GRAESSER; SINGER; TRABASSO, 1994; VIDALABARCA; RICO, 2003).

A pesquisa aqui relatada definiu como seu objetivo examinar a compreensão leitora de alunos de escolas públicas brasileiras do Ensino Fundamental, em suas relações com a escolaridade, a tarefa e a categoria inferencial de questão. Dados o tema e o objetivo, a metodologia se caracterizou pelo uso de quatro tipos de tarefa-Questionário, Múltipla Escolha e Verdadeiro ou Falso - com correspondências das questões no conteúdo e nas características inferenciais -, e Cloze, que possibilitaram a obtenção de dados, a realização de análises e a chegada a resultados conforme o objetivo estabelecido.

Tais resultados constituem-se em contribuição para colocar luz sobre o problema e estimular reflexões que conduzam a soluções possíveis. Nessa perspectiva, neste artigo, os autores expõem primeiramente os fundamentos teóricos sobre leitura, focalizando compreensão leitora, inferência e avaliação da compreensão leitora. A seguir, apresentam a pesquisa, em sua definição, organização e realização. Posteriormente, disponibilizam os resultados e as conclusões da pesquisa, favorecendo o entendimento, pelo leitor, dos processos desenvolvidos e produtos obtidos.

\section{Os fundamentos}

Neste tópico, são apresentados os fundamentos da pesquisa no que se refere à compreensão leitora (eixo da pesquisa), inferência e compreensão leitora (níveis

\footnotetext{
Disponível em http://portal.inep.gov.br. Acesso em 10 setembro 2018.
} 
inferenciais das questões) e avaliação da compreensão leitora (tipos de tarefas utilizados para coleta dos dados).

\section{Compreensão leitora}

Ler significa compreender (COLOMER; CAMPS, 2002), sendo para isso necessário realizar processos cognitivos (SCLIAR-CABRAL, 2008, 2009; LEFFA, 1996). Desse modo, compreensão e processamento são entendidos de forma interligada dentro de um paradigma cognitivo (COSTA; PEREIRA, 2009). Nessa acepção, compreender significa realizar um processo de interação, fundamentado basicamente em dois procedimentos cognitivos - bottom-up e top-down.

O primeiro, o bottom-up, é realizado de forma ascendente, isto é, das partes para o todo, das unidades menores para as maiores. Isso ocorre quando o usuário retira predominantemente do texto as informações de que necessita para efetuar a sua compreensão. Constitui-se num procedimento em que as pistas deixadas pelo autor no texto são a base de um processo de composição, uma vez que as partes gradativamente vão formando o todo (SCLIAR-CABRAL, 2008).

O segundo processo, o top-down (GOODMAN, 1991; SMITH, 1999), caracteriza-se como um movimento descendente, do todo para as partes. Nesse sentido, dirige-se das unidades maiores para as menores, da macroestrutura para a microestrutura. Constituise num procedimento em que os conhecimentos prévios do usuário constituem a base de um processo de decomposição. Tais informações disponíveis permitem ao usuário fazer conexões com as pistas linguísticas.

No estudo aqui proposto, a perspectiva é a de que os dois movimentos (ascendente e descendente) existem e são utilizados interativamente - entre cérebro e texto e entre conhecimentos prévios e pistas linguísticas, passando por todos os níveis linguísticos. Nessa dimensão interativa, a formulação de hipóteses e a sua verificação contam com as unidades linguísticas em seus diversos níveis, sendo utilizadas no duplo movimento. Estudos sobre esse tópico contribuem para o esclarecimento do processamento, ao evidenciarem a formulação de hipótese como um procedimento preditivo que envolve os elementos linguísticos e os da realidade não linguística, estando presente em todas as suas dimensões. Tais estudos verificam essas ocorrências e examinam as variáveis que neles intervêm, cabendo salientar especialmente o de DeLong, Troyer, Kutas (2014), sobre pré-processamento na compreensão de sentenças, e o de Balass, Nelson, Perfetti (2010), sobre processamento da palavra.

Desse modo, os movimentos ascendente e descendente não são excludentes nem seriais, mas convergentes para a situação de compreensão, envolvendo o próprio texto gênero, tipo (ADAM, 2008; BAZERMAN, 2009), o objetivo de leitura e o leitor conhecimentos prévios, estilo cognitivo (KATO, 2007). O sucesso da compreensão está, então, na combinação interativa dos processos ascendente e descendente, considerando os elementos constitutivos da situação de compreensão, em que variáveis se interrelacionam e influenciam as definições do sujeito. 
Um dos modelos interativos de maior aceitação na literatura, o Modelo de Construção-Integração de Kintsch (1998), considera a compreensão um processo inferencial por natureza. Esse modelo consiste em duas dimensões que se relacionam entre si: o texto base, uma representação mental construída a partir de informações explicitadas no texto; e o modelo situacional, uma representação mental realizada a partir do conhecimento prévio do leitor na qual as lacunas do texto são preenchidas por meio do estabelecimento de inferências. O modelo é considerado interativo, pois prevê que, durante a leitura, o leitor integre os elementos do texto-base para, desse modo, construir a representação mental do texto, relacionando informações no nível intratextual e extratextual (BARETTA; PEREIRA, 2018).

\section{Inferência e compreensão leitora}

Segundo Marcuschi (2008), inferência é a atividade que realizamos quando reunimos algumas informações conhecidas para chegarmos a outras informações novas, podendo basear-se em informações textuais explícitas e implícitas, bem como em informações postas pelo leitor.

Spinillo (2013, p.179) considera que:

[...] compreender textos é um processo inferencial por excelência. Inferir decorre do fato que nem tudo está explicitado no texto, tendo o leitor que estabelecer relações entre diferentes passagens e usar seu conhecimento de mundo de maneira a preencher as lacunas e a construir a representação mental adequada e coerente do texto.

A leitura é, portanto, como afirmam Koch e Elias (2011), uma atividade interativa altamente complexa de produção de sentidos, que se realiza com base na relação entre o conhecimento que o leitor traz armazenado na memória e as informações veiculadas no texto. Para as autoras, não se pode falar do sentido do texto e sim de um sentido para o texto, que somente será construído na interação com o leitor.

Desse modo, é fundamental que o leitor reconstrua o percurso trilhado pelo autor, reconhecendo as pistas linguísticas por ele deixadas no texto. É por isso que Kato (2007, p.72) afirma que o texto é "um conjunto de pegadas a serem utilizadas para recapitular as estratégias do autor e através delas chegar aos seus objetivos". Isso significa que, embora não se possa falar em um sentido único do texto, também não se pode considerar que todo entendimento é possível, pois, para que a compreensão seja efetiva, é necessário que as inferências realizadas pelo leitor encontrem amparo na materialidade do texto. Os elementos linguísticos do texto que, em outras concepções de leitura, são muito valorizados ou depreciados, aqui são considerados parte de uma relação triangular entre autor-texto-leitor, na qual o leitor usa os dados fornecidos pelo autor, selecionando as informações relevantes para chegar a um sentido autorizado pelo texto. 
Marcuschi (2008) ilustra essa relação valendo-se da metáfora criada por Dascal (1981) que associa o texto a uma cebola. Segundo o autor, as camadas internas representam as informações objetivas, elementos tipicamente informacionais do texto e que não são passíveis de entendimentos diversos, como nomes, lugares etc. A camada intermediária, por sua vez, é o terreno das inferências, isto é, das diferentes, porém válidas leituras. A camada mais externa é a mais sujeita a equívocos, pois consiste no domínio de nossas crenças e valores. É nesse domínio que surgem os sentidos não autorizados pelo texto.

Esse processo de construção do sentido durante a leitura ocorre, segundo Poersch (1991), em níveis estabelecidos por critérios de abrangência textual e de profundidade de compreensão. O critério de abrangência está relacionado, de acordo com o autor, com a tríplice articulação linguística: lexical, frasal e textual. A compreensão lexical refere-se ao reconhecimento do significado das palavras; já a compreensão frasal consiste em reconhecer o sentido que as palavras assumem na frase, pois, como afirma Poersch (1991, p.130), "o significado de uma frase não corresponde ao somatório do significado das palavras". A compreensão textual, por sua vez, envolve o reconhecimento do sentido global do texto.

O segundo critério, o de profundidade, corresponde à compreensão do sentido explícito, isto é, daquilo que está efetivamente escrito no texto e do sentido implícito, ou seja, o que não está escrito, mas faz parte do texto; e do sentido metaplícito, proveniente de dados externos ao texto, relativos à situação de comunicação.

A construção desses sentidos é realizada por meio de processos que exigem diferentes demandas cognitivas. O primeiro, o conteúdo explícito, deriva de uma atividade de decodificação. O conteúdo implícito exige processos mentais mais complexos, como a inferência e a pressuposição. O metaplícito, por sua vez, é construído a partir do conhecimento prévio de cada indivíduo.

As tarefas propostas neste estudo buscam analisar a compreensão leitora a partir do critério de profundidade, verificando a compreensão do sentido explícito e implícito do texto, considerando os níveis inferenciais.

\section{Avaliação da compreensão leitora}

Estudos sobre compreensão leitora têm apontado diversos fatores que podem influenciar o desempenho em tarefas de compreensão de textos. Um desses fatores refere-se ao tipo da tarefa utilizada nas avaliações (PEREIRA, 2009; CADIME et al., 2017; SPINILLO; ALMEIDA, 2015), estando, entre as mais comuns, Múltipla Escolha, Verdadeiro ou Falso e Questionário, sendo também importante a do Cloze.

Segundo Tinkelman (1967), na Múltipla Escolha, o aluno fica limitado às alternativas apresentadas, havendo pouca ou nenhuma oportunidade de desorientar-se com problemas de qualificação ou de exceção. Vianna (1982) também salienta o fato de que, entre as variedades existentes, esse é o menos sujeito a deficiências comuns aos demais e ajusta-se mais facilmente a diferentes propósitos. Tinkelman (1967) salienta 
que o mesmo pode ser usado com eficiência para medir conhecimentos fundamentais, bem como habilidades intelectuais, sendo o fator acaso consideravelmente reduzido neste tipo de teste, principalmente se forem apresentadas quatro ou cinco alternativas.

Atentando para a complexidade da elaboração das tarefas objetivas, Vianna (1982) apresenta sugestões para qualificar sua construção: desenvolver o item a partir de ideias relevantes; selecionar ideias que possibilitem a elaboração de itens com poder discriminativo; elaborar itens que meçam objetivos importantes; apresentar o item com a maior clareza possível; evitar a inclusão de elementos não funcionais no item; evitar a construção de itens com base em elementos demasiadamente específicos; adaptar a dificuldade do item ao nível do grupo; evitar a inclusão de elementos que possam sugerir a resposta; eliminar o uso de estrutura estereotipada.

No tipo de tarefa Verdadeiro ou Falso, compete ao sujeito indicar se julga verdadeira ou falsa cada uma das afirmações que lhe são apresentadas. Essa forma básica, afirma Gronlund (1974), pode apresentar variações nas quais o examinando deve responder sim ou não, concordo ou discordo, certo ou errado, fato ou opinião, entre outros. Consiste numa tarefa simples e direta do conhecimento do sujeito, que deve se pronunciar sobre a verdade ou a falsidade de uma proposição. Com especial facilidade e economia de tempo, as tarefas de Verdadeiro ou Falso fornecem uma variedade de resultados, tais como interpretação de material novo, análise de material conhecido (apresentado de outra forma), definição ou enunciação de teorias, princípios e leis, avaliação crítica de explicação de fatos ou fenômenos, distinguindo o falso do verdadeiro e fatos de opiniões. Ao julgar o acerto ou não de uma afirmativa, o sujeito demonstra, de forma direta, o seu domínio sobre o conhecimento a ela relacionado.

Segundo Gronlund (1974), a tarefa Verdadeiro ou Falso é uma das mais difíceis de serem elaboradas, pois exige que os enunciados sejam inquestionáveis - ou verdadeiros ou falsos e, ao mesmo tempo, possibilitem medir aspectos importantes do conhecimento. Além disso, por apresentar apenas duas possibilidades de escolha, mesmo o examinando não proficiente tem uma chance de $50 \%$ de fazer a escolha correta sem conhecer a resposta. Outro problema que o autor aponta referente a esse tipo de tarefa diz respeito ao fato de que a escolha feita pelo examinando não fornece indícios sobre o conhecimento que esse realmente possui ou não possui. No caso de o sujeito assinalar como falso um enunciado verdadeiro, a tarefa não permite identificar o conceito errado que o conduziu à resposta escolhida. No caso de o sujeito assinalar como falso um enunciado que é efetivamente falso, não há indícios suficientes para saber se ele conhece a forma verdadeira.

O Questionário, segundo Vianna (1982), constitui um tipo de tarefa denominada de resposta livre ou dissertativo. Tem como característica o fato de o examinando apresentar sua própria resposta em vez de selecioná-la entre várias alternativas oferecidas. A natureza da resposta da questão varia em função do seu tipo. Questões mais simples exigem apenas a recordação de uma informação específica apresentada no texto, enquanto questões mais complexas podem requerer respostas mais elaboradas de análise e estabelecimento de relações. 
Esse tipo de tarefa é recomendável na verificação de objetivos complexos, como, por exemplo, a capacidade de interpretar princípios, realizar inferências, interpretar dados, analisar criticamente uma ideia, estabelecer relações.

Para que o Questionário constitua uma medida eficiente, Vianna (1982) considera importante observar alguns aspectos que dizem respeito à formulação dos itens, à limitação da resposta, à adequação dos itens, à disponibilidade de tempo e à correção dos itens. Em relação à formulação do item, o autor propõe que ele seja suficientemente específico, assim favorecendo o entendimento de como proceder, e seja suficientemente geral, assim permitindo ao sujeito a estruturação da resposta. A limitação da resposta também deve ser previamente considerada pelo elaborador da tarefa, pois questões que permitem respostas amplas apresentam problemas que dificultam sua concretização. O autor aconselha, então, o uso de itens de resposta limitada porque o parâmetro da resposta é mais bem definido, permitindo uma correção simples e uma avaliação objetiva. $\mathrm{O}$ terceiro aspecto apontado por ele diz respeito à adequação do item ao tempo disponível para responder a ele. Para o autor, é importante proporcionar mais tempo que o estimado, para que os sujeitos, independente da velocidade de escrita, possam considerar todas as questões.

O Cloze, por sua vez, é uma tarefa de grande reconhecimento que consiste em "eliminar aleatória ou sistematicamente as palavras de um texto para que o aluno tente a reposição das mesmas, enquanto lê, apoiado no contexto das palavras restantes" (SÖHNGEN, 2002, p.65). Desde sua apresentação por Taylor (1953), a técnica tem sofrido modificações em decorrência dos avanços em sua elaboração e metodologia. A autora defende que, em alguns casos, o procedimento Cloze pode ser utilizado para realizar a mensuração de diversos tipos de variáveis do processo de comunicação e compreensão leitora.

Embora as definições sejam variadas, a que mais se popularizou é aquela que o caracteriza como procedimento que utiliza textos com um mínimo de 250 a 300 palavras, eliminando cada quinta palavra do texto e preservando o primeiro e o último parágrafos intactos. Assim, é o comprimento do texto escolhido que determinará o processo de apagamento das palavras, orientando a contagem dos intervalos. Devido a sua configuração, o cloze é muito utilizado em pesquisas envolvendo a compreensão leitora e a leiturabilidade dos textos.

Esses quatro tipos de tarefa - Múltipla Escolha, Verdadeiro ou Falso, Questionário e Cloze - foram utilizados na pesquisa em exposição. No próximo tópico, sua organização e sua realização são apresentadas, tendo como base os fundamentos teóricos já expostos.

\section{A organização da pesquisa}

Como já exposto, a pesquisa teve como objetivo analisar o desempenho em compreensão leitora de alunos do Ensino Fundamental em relação à compreensão leitora em sua natureza inferencial, considerando categorias de inferência, tipos de tarefas e escolaridade. 
A amostra da pesquisa foi constituída por 62 participantes, distribuídos entre os três anos escolares: 26 do $6^{\circ}$ ano, 20 do $7^{\circ}$ ano e 16 do $8^{\circ}$ ano. Os participantes eram de ambos os sexos, com idades entre 11 e 15 anos - dentro da faixa escolar regular -, de uma escola pública da cidade de Porto Alegre, Rio Grande do Sul.

Em cada ano escolar, os participantes foram distribuídos em relação ao tipo de tarefa, por meio de sorteio: 16 participantes - Múltipla Escolha (ME), 15 participantes Verdadeiro ou Falso (VF), 17 participantes - Questionário (Q) e 14 participantes Cloze (CL). Os participantes foram assim organizados de modo a permitir a associação dos escores de compreensão leitora à escolaridade e ao tipo de tarefa considerando a característica inferencial de cada questão.

Foram utilizadas, então, quatro tarefas de compreensão leitora com esses quatro formatos diferentes, todas com o mesmo texto de apoio, a crônica Prova Falsa, de Stanislaw Ponte Preta. A seleção do texto foi realizada considerando a adequação do conteúdo, da linguagem e da extensão aos alunos participantes e a exigência de uso de inferências para realização da compreensão. Foram realizadas adaptações em algumas estruturas, com o intuito de torná-lo mais apropriado ao universo linguístico do públicoalvo da pesquisa (BARETTA; PEREIRA, 2018).

A seguir, observa-se a descrição de cada tarefa:

a. Tarefa de Múltipla Escolha: constituída de seis questões, cada uma apresenta um questionamento em relação ao texto, oferecendo cinco alternativas possíveis como resposta, sendo apenas uma a resposta adequada.

b. Tarefa de Verdadeiro ou Falso: constituída de seis questões, a partir das informações presentes nas questões das demais tarefas, contém afirmações em relação ao texto, devendo o participante assinalar V (verdadeiro) ou $\mathrm{F}$ (falso) e justificar essa segunda escolha.

c. Tarefa de Questionário: constituída de seis questões abertas, apresentam correspondência aos conteúdos focalizados nas demais tarefas.

d. Tarefa de Cloze: constituída de 36 lacunas, com intervalo de cinco palavras, a serem preenchidas, utiliza o mesmo texto das demais tarefas.

Considerando que, nesta pesquisa, a concepção de compreensão adotada é aquela que a descreve como atividade essencialmente inferencial (KINTSCH, 1998), foi buscado apoio, para a elaboração das questões que constituíram as tarefas, em estudos que descrevessem diferentes tipos de inferências. Então, com base em estudos de Graesser, Singer e Trabasso (1994), de Giasson (2000) e de Vidal-Abarca e Rico (2003), foram estabelecidas quatro categorias, sendo a primeira com informação não inferencial e as demais com informações inferenciais em diferentes modos. As quatro categorias são descritas e exemplificadas ${ }^{2}$ a seguir:

As questões foram elaboradas com base no texto "Prova falsa", de Stanislaw Ponte Preta. 
a. Categoria 1: a informação está explícita, podendo ser diretamente encontrada no texto sem uso dessa estratégia.

Questão: Como deveria ser o cachorro para agradar o dono da casa?

Resposta esperada: O cachorro deveria ser obediente e com o mínimo de educação.

Explicação: Para responder à questão, o leitor deve localizar informações claramente expressas no texto.

b. Categoria 2: a inferência decorre de relações intratextuais, pois entre proposições do texto.

Questão: O que fez o homem vencer a guerra contra o cachorro?

Resposta esperada: $\mathrm{O}$ homem venceu a guerra porque o cachorro começou a fazer pipi onde não devia.

Explicação: Para responder à questão, o leitor deve apoiar-se em uma informação implícita. No texto, não há menção explícita entre o fato de o cãozinho começar a fazer pipi onde não devia e o fato de o dono vencer a guerra contra o cão. O leitor precisa acrescentar "porque" entre as duas frases para poder responder ao item.

c. Categoria 3: a inferência decorre de informações extratextuais baseadas nos conhecimentos prévios do leitor, cabendo-lhe associá-las às proposições do texto.

Questão: De quem era o pipi no vestido da mulher?

Resposta esperada: O pipi era do dono do cachorro.

Explicação: Para responder à questão, o leitor deve acionar seus conhecimentos prévios sobre as circunstâncias em que uma pessoa sente remorso, de modo a relacionar o motivo do remorso à autoria da ação questionada na pergunta.

d. Categoria 4: a inferência depende do sentido macroestrutural do texto e contribui para estabelecer a coerência global.

Item: Por que o título do texto é Prova Falsa?

Resposta esperada: O título do texto é Prova Falsa porque o dono criou uma prova falsa (o pipi) contra o cachorro para mandá-lo embora.

Explicação: Para responder à questão e explicar o sentido do título, o leitor deve organizar e relacionar as diferentes informações presentes no texto.

As seis questões que compõem as tarefas de compreensão leitora estão distribuídas conforme descrição na Tabela 1. 
Tabela 1 - Questões por categoria

\begin{tabular}{|c|c|c|c|c|}
\hline \multirow{2}{*}{ Questão da tarefa } & \multicolumn{4}{|c|}{ Categorias } \\
\hline & 1 & 2 & 3 & 4 \\
\hline (Q1) Como a família conseguiu o cachorro? & $\mathrm{X}$ & & & \\
\hline $\begin{array}{l}\text { (Q2) Como deveria ser o cachorro para agradar o dono da } \\
\text { casa? }\end{array}$ & $\mathrm{X}$ & & & \\
\hline (Q3) Por que o homem venceu a guerra contra o cachorro? & & $\mathrm{X}$ & & \\
\hline $\begin{array}{l}\text { (Q4) Por que o homem deu o animal a um amigo que adora } \\
\text { cachorros? }\end{array}$ & & $\mathrm{X}$ & & \\
\hline (Q5) De quem era o pipi no vestido da mulher? & & & $\mathrm{X}$ & \\
\hline (Q6) Por que o título do texto é Prova Falsa? & & & & $\mathrm{X}$ \\
\hline
\end{tabular}

Fonte: Elaboração própria.

Quanto à correção das tarefas, cada resposta correta somou um ponto. Na tarefa $\mathrm{VF}$, as respostas falsas foram consideradas corretas somente quando justificadas adequadamente.

A coleta dos dados foi realizada na escola por bolsistas graduandos e pós-graduandos, preparados para sua realização. Ocorreu no turno regular, durante as aulas de Língua Portuguesa de cada turma. Cada aplicação durou em média 40 minutos (um período de aula). Cada um dos alunos das turmas participantes respondeu a apenas uma das tarefas, com base em sorteio, visto que o texto é o mesmo para os diferentes tipos de instrumentos. A Tabela 2 a seguir mostra a distribuição de alunos por tipo de tarefa e por ano escolar.

Tabela 2 - Distribuição de alunos por tarefa e por ano escolar

\begin{tabular}{c|c|c|c}
\hline \multirow{2}{*}{ Tipo de tarefa } & \multicolumn{3}{|c}{ Ano escolar } \\
\cline { 2 - 4 } & $6^{\circ}$ ano & $7^{\circ}$ ano & $8^{\circ}$ ano \\
\hline ME & 7 & 5 & 4 \\
Q & 7 & 5 & 5 \\
CL & 6 & 5 & 3 \\
VF & 6 & 5 & 4 \\
\hline Total & 26 & 20 & 16 \\
\hline
\end{tabular}

Fonte: Elaboração própria.

ME: Múltipla escolha Q: Questionário CL: Cloze VF: Verdadeiro ou falso

No tópico seguinte são apresentados os resultados obtidos com base nos dados coletados. 


\section{Resultados e discussão}

Como apresentado, foram submetidos aos instrumentos avaliativos 62 diferentes sujeitos, fornecendo uma única variável quantitativa dependente (acertos), controlada ou segmentada por dois fatores ou variáveis qualitativas independentes (tarefa e ano de escolaridade). O tratamento estatístico dos dados foi realizado com base na análise de variância (ANOVA) de dupla classificação (Two-way ANOVA). Desse modo, os resultados expostos decorrem dessas variáveis, conforme objetivos traçados e design da pesquisa.

Cada variável (ano e tarefa) apresenta um efeito principal. Um efeito interação ou combinado (neste caso ano x tarefa) é também assumido pela técnica e testado. $\mathrm{O}$ teste é executado através da estatística $\mathrm{F}$ e a significância (valores iguais ou inferiores a $0,05=5 \%$ ) de $\mathrm{F}$ mostram se aquele fator ou interação é significativo para o resultado (variável dependente ou acertos). No caso do grupo investigado, as duas variáveis se mostraram significativas, indicando que, tanto o tipo de tarefa quanto o nível de escolaridade (ano), quando analisados individualmente, influenciam o desempenho em compreensão leitora. No entanto, isso não ocorre quando se analisam os dados combinados (Ano x Tarefa), uma vez que a interação entre essas variáveis não foi significativa, conforme Tabela 3.

Tabela 3 - Testes dos efeitos principais e do efeito interação

\begin{tabular}{c|c|c|c|c|c}
\hline & GL & $\begin{array}{c}\text { Soma de } \\
\text { Quadrados }\end{array}$ & $\begin{array}{c}\text { Quadrados } \\
\text { Médios }\end{array}$ & F & Significância \\
\hline Tarefa & 3 & 27,17 & 9,05 & 5,16 & 0,003 \\
Ano & 2 & 18,75 & 9,37 & 5,34 & 0,007 \\
Tarefa x Ano & 6 & 7,42 & 1,23 & 0,70 & 0,646 \\
Resíduos & 50 & 87,74 & 1,75 & & \\
\hline
\end{tabular}

Fonte: Elaboração própria.

Um dos objetivos que nortearam essa pesquisa foi comparar o desempenho dos alunos dos diferentes níveis de escolaridade com relação à compreensão em leitura. A tabela 4 apresenta as médias de cada uma das variáveis Ano independente da variável Tarefa. 
Tabela 4 - Média dos acertos por ano escolar

\begin{tabular}{c|c|c|c|c}
\hline \multirow{2}{*}{ Ano } & \multirow{2}{*}{ Médias } & \multirow{2}{*}{$\begin{array}{c}\text { Erro } \\
\text { padrão }\end{array}$} & \multicolumn{2}{|c}{ Intervalo de 95\% de confiança } \\
\cline { 4 - 5 } & & 1,41 & Limite inferior & Limite superior \\
\hline $6^{\mathbf{0}}$ & 3,0 & 1,44 & 2,42 & 3,57 \\
$7^{\text {o }}$ & 3,25 & 1,49 & 3,51 & 3,92 \\
$8^{\text {o }}$ & 4,31 & & 5,10 \\
\hline
\end{tabular}

Fonte: Elaboração própria.

Conforme observado na Tabela 4 , o rendimento global dos alunos do $6^{\circ}$ ano foi de 3,0, dos alunos do $7^{\circ}$ ano foi de 3,25 e dos alunos do $8^{\circ}$ ano foi de 4,31. Também é possível observar o erro padrão apresentado, que define o quanto se pode estar errando ao afirmar o acerto médio de cada nível. O intervalo, que está expresso nas duas últimas colunas, considera as variações possíveis considerando o erro padrão. Desse modo, os alunos do $6^{\circ}$ ano apresentaram um acerto mínimo de 2,42 e um máximo de 3,57 . Já os alunos do $7^{\circ}$ ano apresentaram um acerto mimo de 2,57 e um máximo de 3,92 . Os alunos do $8^{\circ}$ ano, por sua vez, apresentaram um acerto mínimo de 3,51 e um máximo de 5,10.

A tabela demonstra a evolução dos participantes entre os anos de escolaridade e aponta para uma possível evolução para outros grupos. Embora esses resultados estejam inseridos em situação específica de uma escola, trata-se de algo a ser considerado positivamente, visto que são grandes e reconhecidas as dificuldades de aprendizado da leitura, evidenciadas nos dados oficiais. No entanto, é importante lembrar que o professor deve avaliar, na prática escolar educativa, se essa diferença entre os níveis de escolaridade significa uma evolução substancial na compreensão leitora.

Outro objetivo que norteou a pesquisa foi analisar o desempenho em compreensão leitora dos participantes em relação ao tipo de tarefa realizada. A Tabela 5, a seguir, apresenta a média de acerto por tarefa nos anos escolares investigados.

Tabela 5 - Média dos acertos por tarefa

\begin{tabular}{ccc}
\hline Tarefa & N & Média \\
\hline ME & 16 & 4,43 \\
Q & 17 & 3,29 \\
CL & 14 & 3,28 \\
VF & 15 & 2,60 \\
\hline
\end{tabular}

Fonte: Elaboração própria.

É possível observar, com base nos resultados evidenciados na tabela, que a tarefa de Múltipla Escolha obteve a média mais elevada - 4,43. A tarefa de Verdadeiro ou Falso, por sua vez, obteve a menor média $(2,60)$ entre os quatro tipos de tarefas 
investigadas. As tarefas de Questionário e Cloze apresentaram médias intermediárias e muito semelhantes entre si -3,29 e 3,28, respectivamente.

A média mais elevada, obtida pela tarefa de Múltipla Escolha, pode ser justificada pelo fato de o aluno ser beneficiado pela apresentação de alternativas de resposta, contribuindo para o processo de reflexão e avaliação sobre o que poderia ser mais plausível em relação ao questionamento proposto (PEREIRA, 2008, 2018). Desse modo, os resultados apontam que, nos grupos investigados, esse tipo de tarefa favorece a percepção, por parte do participante, da perspectiva assumida na questão, e o auxilia a relacionar as informações apresentadas nas alternativas às informações presentes no texto e a identificar qual seria a resposta mais adequada.

A tarefa de Questionário apresentou a segunda média mais elevada, evidenciando que a possibilidade de o aluno organizar sua própria perspectiva também é indicada para avaliar a compreensão leitora de alunos desses níveis. No entanto, trata-se de uma média intermediária, visto que a média obtida nessa tarefa se aproxima mais da média da tarefa de Cloze do que da média da tarefa de Múltipla Escolha.

$\mathrm{O}$ fato de a tarefa de Verdadeiro ou Falso ter apresentado a menor média pode ser explicado pelas características dessa tarefa. Como exige do participante a apresentação de justificativa para as afirmações consideradas falsas, em decorrência de igual possibilidade de acerto e erro, talvez não seja tão familiar e de entendimento fácil e rápido para participantes desses níveis escolares.

Tais resultados podem guiar os professores no planejamento de suas aulas e avaliações, pois sugerem que, com alunos dos anos escolares analisados, as tarefas com alternativas e com itens abertos são mais eficazes em relação àquelas de julgamento entre verdadeiro ou falso, exigindo uma justificativa, que, aparentemente, indica um fator complicador para esses alunos, assim como a técnica utilizando lacunas.

A pesquisa buscou também verificar o desempenho dos participantes com relação ao nível de inferência exigido. Esses dados são apresentados na tabela 6 a seguir.

Tabela 6 - Número e porcentagem de acerto por categoria - não inferencial / inferencial

\begin{tabular}{c|c|c|c|c}
\hline \multirow{2}{*}{ Anos } & \multicolumn{4}{|c}{ Categorias } \\
\cline { 2 - 5 } & Categoria 1 & Categoria 2 & Categoria 3 & Categoria 4 \\
\hline $\mathbf{6}^{\mathbf{0}}$ ano & $36(90 \%)$ & $18(45 \%)$ & $3(15 \%)$ & $7(35 \%)$ \\
$\mathbf{7}^{\mathbf{a}}$ ano & $26(86,6 \%)$ & $13(43,3 \%)$ & $4(26,6 \%)$ & $4(26,6 \%)$ \\
$\mathbf{8}^{\circ}$ ano & $23(88,4 \%)$ & $16(61,5 \%)$ & $7(53,8 \%)$ & $9(69,2 \%)$ \\
\hline
\end{tabular}

Fonte: Elaboração própria.

Observa-se que, em todos os grupos, o número e o percentual de acertos tendem a diminuir à medida que progride a categoria inferencial da questão, ou seja, menos acertos são verificados. Isso não ocorreu somente na comparação entre as categorias 3 e 4 no grupo do $6^{\circ}$ e do $8^{\circ}$ ano. 
Em relação aos anos escolares, é possível observar, comparando-os, que as respostas corretas foram mais frequentes entre os alunos do $8^{\circ}$ ano do que entre os alunos do $7^{\circ} \mathrm{e}$ do $6^{\circ}$ anos. No entanto, as respostas corretas não foram mais frequentes entre os alunos do $7^{\circ}$ ano em relação aos do $6^{\circ}$ ano, exceto no que diz respeito à categoria 3 . Apesar disso, de modo geral, esses dados indicam que o nível de escolaridade está associado à realização de inferências, visto que os alunos do $8^{\circ}$ ano obtiveram mais acertos que os alunos dos demais grupos, de níveis escolares inferiores.

Comparando os dados referentes a cada categoria inferencial, nota-se desempenho significativamente superior na categoria 1 (Q1 e Q2 da Tabela 1) em relação às demais categorias. Essa diferença fica ainda mais evidente na comparação entre o percentual de acerto obtido na categoria 1 em cada grupo e o percentual de acerto obtido nas demais categorias em conjunto. No $6^{\circ}$ ano, por exemplo, $90 \%$ dos alunos deram respostas corretas na categoria 1, enquanto o percentual de acerto nas categorias 2, 3 e 4 alcançou $31,6 \%$. Já no $7^{\circ}$ ano, nas categorias 2,3 e 4 foi obtido $32,1 \%$ de acerto, enquanto somente na categoria 1 o percentual de acerto foi de $86,6 \%$. O grupo do $8^{\circ}$ ano, por sua vez, teve $88,4 \%$ de acerto na categoria 1 e $61,5 \%$ nas demais categorias. Esses resultados se devem ao fato de as duas primeiras questões, de categoria 1, exigirem a recuperação de informações que estão claramente expressas, enquanto as demais questões exigem a realização de algum tipo de inferência. Nota-se, portanto, que os alunos têm mais dificuldades quando as questões exigem procedimentos inferenciais complexos.

O tipo de inferência exigida na categoria 2 (Q3 e Q4 da tabela 1) é baseada nas relações causais entre proposições do texto, enquanto aquela exigida na categoria 3 (Q5 da tabela 1) decorre de informações que são acrescentadas com base na relação entre os conhecimentos anteriores do leitor e o material linguístico, ou seja, o texto. Os dados da tabela 6 sugerem que inferências baseadas em informações intratextuais são realizadas com mais facilidade do que as baseadas em informações extratextuais. Isso é observado pelos percentuais de acertos maiores na categoria 2 em comparação com a categoria 3. Apesar disso, nota-se que ocorre uma diminuição dessa diferença comparando a evolução do ano de escolaridade.

Por fim, a categoria 4 (Q6 da tabela 1) exige a realização de inferência que contribui para estabelecer a coerência global do texto. Os percentuais de acerto nessa categoria foram maiores no grupo do $6^{\circ}$ e do $8^{\circ}$ anos em comparação com o desempenho dos mesmos grupos na categoria 3; ambos os níveis obtiveram o mesmo percentual de acertos no grupo do $7^{\circ}$ ano.

Em pesquisa realizada com alunos do $4^{\circ}$ e $5^{\circ}$ anos do Ensino Fundamental, pelo NUCCLIN do PPGL da PUCRS, ao qual estão integradas as autoras, os dados sugeriram que alunos dessa faixa escolar têm dificuldade em realizar inferências que exijam a análise de aspectos macroestruturais do texto, sendo capazes de compreender informações locais, mas incapazes de relacioná-las em âmbito global. Os resultados mostraram que o desempenho dos participantes dos dois grupos foi consideravelmente inferior em comparação aos demais níveis, com percentuais de acerto que não ultrapassaram os $30 \%$. Já em estudo realizado com $6^{\circ}$ e $7^{\circ}$ anos do Ensino Fundamental anteriormente 
(BARETTA e PEREIRA, 2018), revelou-se que, nesse nível de escolaridade, os alunos mostram mais facilidade na realização de inferências globais, sugerindo que essa habilidade evolui com a escolaridade. As conclusões das autoras corroboram, portanto, os resultados aqui apresentados.

No que diz respeito à igualdade entre os tipos de tarefa investigados, a relação entre eles é comprovada por meio de teste estatístico de comparações múltiplas (Tukey). O teste avalia em que medida os tipos de tarefa oferecem os mesmos resultados na investigação da compreensão leitora. A tabela 7, a seguir, apresenta os resultados dessa análise.

Tabela 7 - Comparações múltiplas - Fator Teste

\begin{tabular}{cccccc}
\hline Teste Estatístico & Tarefas & Centro & $\begin{array}{c}\text { Limite } \\
\text { Inferior }\end{array}$ & $\begin{array}{c}\text { Limite } \\
\text { Superior }\end{array}$ & p-valor \\
\hline \multirow{6}{*}{ Tukey } & ME-CL & 1,154 & $-0,204$ & 2,508 & 0,123 \\
& Q-CL & 0,008 & $-1,329$ & 1,346 & 0,999 \\
& VF-CL & $-0,685$ & $-2,063$ & 0,691 & 0,556 \\
& Q-ME & $-1,143$ & $-2,434$ & 0,147 & 0,100 \\
& VF-ME & $-1,837$ & $-3,169$ & $-0,505$ & 0,003 \\
\hline
\end{tabular}

Fonte: Elaboração própria.

Observa-se, a partir dos dados da tabela 7, que houve diferença significativa entre VF e ME somente ( $p=0,003$, ou seja, $p<0,05)$. Portanto, significa que as tarefas não são equivalentes e a utilização de uma ou outra influencia o resultado. Os dados apresentados na tabela 5, referente à média de acertos por tarefa, ilustra essa grande diferença ao mostrar a de Múltipla Escolha em um extremo da tabela, com a maior média de acertos, e a de Verdadeiro ou Falso no outro extremo, com a menor média de acertos.

Quanto aos outros grupos de tarefas, não houve diferença significativa em nenhum deles ( $p>0,05)$. Com isso, sugere-se que há determinada equivalência entre as demais tarefas e a utilização de uma ou outra como forma de avaliação da compreensão leitora não influencia os resultados.

Apresentados os dados coletados e os resultados obtidos na pesquisa, são expostas, a seguir, as conclusões do estudo.

\section{Conclusões}

O estudo aqui relatado teve por objetivo investigar a compreensão leitora de alunos de $6^{\circ}, 7^{\circ}$ e $8^{\circ}$ anos do Ensino Fundamental de escola pública brasileira no que se refere às relações entre o ano de escolaridade, o tipo de tarefa e as categorias inferenciais de cada questão das tarefas. Considerando que se trata do nível intermediário da Educação 
Básica, constituindo níveis de passagem entre os Anos Iniciais do Ensino Fundamental e o Ensino Médio, compreender como ocorre a evolução da compreensão leitora nessa etapa pode contribuir com o planejamento dos professores, ajudando, também, a amenizar dificuldades em leitura evidenciadas, de modo geral, pelos estudantes brasileiros.

Conforme os resultados do SAEB 2017, já apresentados anteriormente, observase que há pouca progressão nos resultados comparando os de 2017 aos de 2015: nos anos finais do Ensino Fundamental, em 2017, a pontuação de Língua Portuguesa foi de 253,74, enquanto a de 2015 foi de 247,33. Esses resultados sugerem que a escola tem conseguido avançar pouco - quando avança - e que o ensino e o aprendizado apresentam dificuldades nesse sentido. Relacionando esses dados oficiais aos resultados decorrentes desta pesquisa, percebe-se que o nível de escolaridade de fato influencia nos resultados de compreensão leitora, assim como o tipo de tarefa e as categorias inferenciais das questões.

Percebe-se, com isso, que o trabalho com categorias inferenciais é indicado para auxiliar no desenvolvimento da compreensão leitora em sala de aula, visto que existem potencialidades reveladas nesta pesquisa no que se refere à exploração das informações dos textos considerando tais categorias. Além disso, o tipo de tarefa também levou os participantes a alcançarem desempenhos diferentes, sugerindo que trabalhar com diferentes tipos de tarefas em sala de aula também é um caminho para desenvolver a compreensão leitora, considerando que cada atividade explora as informações de formas diferentes e exige que o aluno percorra caminhos cognitivos distintos para realizá-las.

Para alcançar os objetivos do estudo, as autoras apoiaram-se teoricamente na concepção de leitura como processo cognitivo (COLOMER; CAMPS, 2002), que envolve movimentos ascendentes e descendentes que ocorrem de forma interativa (SCLIAR-CABRAL, 2008; GOODMAN, 1991; SMITH, 2003). Tendo em vista um dos principais objetivos do estudo - investigar a influência da categoria inferencial das questões na compreensão -, o suporte teórico encontra-se, também, na concepção de compreensão como atividade de natureza inferencial (KINTSCH, 1998; MARCUSCHI, 2008; GIASSON, 2000; SPINILLO; ALMEIDA, 2015), que envolve elementos explícitos e implícitos (POERSCH, 1991). Quanto à avaliação da compreensão leitora, estudos específicos embasaram suas definições (GRONLUND, 1974; TINKELMAN, 1967).

Os dados teóricos aqui apresentados apoiaram a elaboração das tarefas de compreensão leitora - abordando categorias inferenciais das questões, gerando os dados empíricos coletados junto aos estudantes dos $6^{\circ}, 7^{\circ}$ e $8^{\circ}$ anos do Ensino Fundamental, participantes dessa pesquisa. Assim, constituem-se como resultados do estudo os próprios dados teóricos, as tarefas e as informações a respeito das condições de leitura dos estudantes.

No que se refere aos desempenhos globais de cada grupo, comparando os anos escolares, nota-se a frequência maior de respostas corretas conforme aumenta o nível de escolaridade. A média dos acertos de cada grupo ficou, respectivamente, 3,0; 3,25 
e 4,31; evidenciando evolução do $6^{\circ}$ para o $7^{\circ}$ ano e do $7^{\circ}$ para o $8^{\circ}$. Possivelmente, esses resultados estão relacionados às propriedades do processamento cognitivo desses sujeitos, indicando que, conforme o desejado, a evolução da escolaridade pode cooperar para uso de procedimentos cognitivos mais complexos.

Considerando o desempenho dos participantes em relação ao tipo de tarefa realizada, a média mais elevada foi a de Múltipla Escolha, as médias intermediárias foram as do Questionário e do Cloze e as menores médias foram as do Verdadeiro ou Falso. Os resultados permitem concluir que o Verdadeiro ou Falso oferece dificuldades aos participantes dessa faixa escolar, principalmente por exigir uma justificativa para as alternativas consideradas falsas, procedimento fundamental para a resposta ter sido considerada correta. A média do Múltipla Escolha indica, pelo contrário, que se trata de uma atividade com a qual os alunos dessa faixa escolar possuem maior familiaridade, talvez pela frequência de seu uso no cotidiano. Nesse caso, o aluno tem seus procedimentos cognitivos facilitados em decorrência da apresentação de alternativas de resposta que o auxiliam em suas reflexões.

Quanto às comparações estabelecidas em relação às categorias inferenciais, os resultados sugeriram que o ano de escolaridade está associado à capacidade de realizar inferências, já que os alunos do $8^{\circ}$ ano apresentaram número de acertos mais elevado em relação aos alunos dos demais níveis escolares. Isso não ocorreu, entretanto, no que diz respeito à comparação entre o $7^{\circ}$ e o $6^{\circ}$ ano, exceto em relação à categoria 3 . Além disso, foi possível observar que, de modo geral, em todos os níveis escolares, o percentual de acertos diminuiu à medida que progrediu a categoria inferencial de cada questão. Isso não ocorreu apenas na comparação entre a categoria 3 e a categoria 4 nos grupos do $6^{\circ}$ e do $8^{\circ}$ anos, o que sugere maior dificuldade, para os alunos dessas faixas escolares, a resolução de questões que envolvem informações extratextuais, que estão fora do texto, em relação àquelas que contribuem para o sentido global do texto.

O teste de comparações múltiplas (Tukey) foi utilizado para avaliar a igualdade entre os tipos de tarefas. Os resultados mostraram que as tarefas de Múltipla Escolha e Verdadeiro ou Falso não são equivalentes, visto que a diferença foi significativa entre os resultados de uma e outra. Tal resultado evidencia a diferença entre as exigências dos dois tipos de tarefa: enquanto a tarefa de Múltipla Escolha oferece alternativas que podem facilitar o processamento cognitivo sobre uma resposta plausível para a questão, como já observado, a tarefa de Verdadeiro ou Falso torna-se mais complexa por exigir, além da identificação da afirmativa como verdadeira ou falsa, uma justificativa para aquelas consideradas falsas.

As comparações entre os demais tipos de tarefas não apontaram diferenças significativas, indicando que há equivalências entre elas. Isso significa que a utilização de qualquer uma como forma de mensurar a compreensão leitora não influencia significativamente os resultados.

A observação dos resultados no que se refere aos desempenhos por categorias inferenciais evidenciou algumas peculiaridades, especialmente no que se refere às respostas por ano escolar. Entre elas, cabe registrar esses desempenhos: no $6^{\circ}$ ano, na 
categoria 1, mais elevados do que os demais; no $8^{\circ}$ ano, nas categorias 2,3 e 4 , os mais elevados dos três anos escolares; no $7^{\circ}$ ano, na categoria 3 , mais elevados que o $6^{\circ}$ ano. Entre essas peculiaridades, observa-se paralelamente que, no $8^{\circ}$ ano, na categoria 1 , os resultados foram inferiores aos do $6^{\circ}$ ano, embora em pequena proporção; no $7^{\circ}$ ano, por sua vez, os resultados foram inferiores nas categorias 1, 2 e 4. Apesar dessas peculiaridades, convém registrar que, como já dito, no resultado global, há um avanço progressivo nos resultados, considerando a variável escolaridade.

Há, nas condições de ensino, elementos que talvez possam colaborar para o entendimento dessas peculiaridades, sendo isso importante, embora o objetivo da pesquisa - verificar a compreensão leitora, tendo sido utilizadas para a formulação das questões categorias inferenciais - tenha sido alcançado.

Um desses elementos pode estar relacionado à organização do trabalho de cada escola, de cada ano escolar e de cada professor, pois, embora existam documentos oficiais que direcionam a prática do professor em sala de aula, há espaço de liberdade de planejamento e execução pelas instituições e seus docentes, considerando os conhecimentos destes e as condições de cada ano escolar.

Por parte dos alunos também há particularidades que podem interferir nesses resultados: em alguns casos, o público da escola, por conjunturas familiares, pode ter a necessidade de troca de escola, contribuindo possivelmente para a descontinuidade do processo de ensino e aprendizagem. Nessas circunstâncias, alguns alunos podem não ter desenvolvido os conhecimentos para o trabalho inferencial, não havendo também garantias de que o professor esteja apto a realizá-lo.

A partir do estudo realizado, percebe-se, então, a importância da realização de inferências para a compreensão na escola, visto que são as relações intratextuais, extratextuais e globais que determinarão o que será compreendido, envolvendo a materialidade linguística, os conhecimentos prévios do leitor, o seu estilo cognitivo e toda a situação contextual do momento de leitura. Desse modo, nota-se maior dificuldade dos alunos no processamento de informações implícitas, que necessitam ser relacionadas àquelas armazenadas na memória, constituindo-se, assim, em obstáculo para o processamento das unidades linguísticas e para a chegada à compreensão textual.

De modo a contribuir para o planejamento pedagógico do ensino da leitura nessa faixa escolar, salienta-se a importância da reflexão sobre situações didáticas que objetivem desenvolver a análise de diferentes categorias de inferência por parte dos alunos. É fundamental que esses estejam preparados para manipular e compreender diferentes tipos de informações, sejam elas intratextuais, extratextuais ou globais, pois todas são essenciais para a realização efetiva do processo de compreensão. Além disso, os dados referentes aos diferentes tipos de tarefa podem ser utilizados na seleção dos melhores a serem utilizados para o desenvolvimento da compreensão leitora nessa faixa escolar. Esses dados servem, ainda, para evidenciar quais precisam ser mais desenvolvidos com alunos dessa faixa escolar, dada a sua dificuldade com determinados formatos e exigências. 


\section{Agradecimentos}

As autoras agradecem as contribuições das doutorandas Gabrielle Perotto (bolsista CAPES) e Giselle Liana Fetter (bolsista CAPES) e das bolsistas de Iniciação Científica Ágata Marmitt (FAPERGS), Dhaiele Santana Schmidt (BPA/PUCRS) e Diovana da Silveira Baldez (FAPERGS).

PEREIRA, V.; BARETTA, D.; BORGES, C. Reading comprehension of students of primary school II: A study on performance using different types of tasks and inferential categories. Alfa, São Paulo, v.66, 2022.

- ABSTRACT: This research had the goal to examine the reading comprehension of primary school students according to their level of education and the proposed tasks. The research subjects were 62 students from the 6th to the 8th year of Primary School II, from a public school in the city of Porto Alegre (RS / Brazil). Data collection was performed using Questionnaire, True or False and Multiple Choice. The questions had a correspondence with the contents, inferential categories, and Cloze. Each subject answered only one task. This distribution was carried out randomly in each class of students. The collected data were organized and treated statistically, thus enabling the following results: a significant difference in reading comprehension ( $p=0.007$ ) in regard to the level of education, indicating progression of scores as the schooling process goes on; a significant difference $(p=0.003)$ regarding the type of task, in which Multiple Choice task presented the highest average score (4.43), the True or False task showed the lowest average score (2.60) and the Quiz tasks and Cloze indicated intermediate averages (3.29 and 3.28, respectively); and a development on the ability to make inferences (relating to the inferential category) was seen as the educational level increases.

- KEYWORDS: reading comprehension; inferential category of questions; primary school.

\section{REFERÊNCIAS}

ADAM, J.-M. A Linguística: introdução à análise textual dos discursos. São Paulo: Cortez, 2008.

BARETTA, D.; PEREIRA, V.W. Compreensão literal e inferencial em alunos do Ensino Fundamental. Signo, Santa Cruz do Sul, v.43, n.77, p.53-61, 2018. Disponível em: https://online.unisc.br/seer/index.php/signo/article/view/11533/pdf. Acesso em: 03 mar. 2020.

BALASS, M.; NELSON, J. R.; PERFETTI, C. A. Word learning: An ERP investigation of word experience effects on recognition and word processing. Contemporary educational psychology, San Diego, v.35, n.2, p.126-140, 2010. Disponível em: https:// doi.org/10.1016/j.cedpsych.2010.04.001. Acesso em: 01 abr. 2019. 
BAZERMAN, C. Handbook of research on writing: history, society, school, individual, text. Abingdon: Routledge, 2009.

CADIME, I. et al. Compreensão de textos: diferenças em função da modalidade de apresentação da tarefa, tipo de texto e tipo de pergunta. Análise Psicológica, Lisboa, v.35, n.3, p.351-366, 2017. Disponível em: https://doi.org/10.14417/ap.1234. Acesso em: 01 abr. 2019.

COLOMER, T.; CAMPS, A. Ensinar a ler e ensinar a compreender. Porto Alegre: Artes Médicas, 2002.

COSTA, J. C.; PEREIRA, V. W. Linguagem e cognição. Porto Alegre: EDIPUCRS, 2009.

DASCAL, M. Strategies of understanding. In: PARRET, H.; BOUVERESSE, J. (ed.). Meaning and understanding. Berlin; New York: W. De Gruyter, 1981. p.327-352.

DELONG, K. A.; TROYER, M.; KUTAS, M. Pre-processing in sentence comprehension: Sensitivity to likely upcoming meaning and structure. Language and linguistics compass, Chichester, v.8, n.12, p 631-645, 2014. Disponível em: https://doi.org/10.1111/ lnc3.12093. Acesso em: 01 abr. 2019.

GIASSON, J. A compreensão na leitura. Lisboa: ASA, 2000.

GOODMAN, K. S. Unidade na leitura - um modelo psicolinguístico transacional. Letras de Hoje, Porto Alegre, n.86, p.9-43, 1991.

GRAESSER, A. C.; SINGER, M.; TRABASSO, T. Constructing inferences during narrative text comprehension. Psycological Review, Princeton, v.101, n.3, p.371-395, 1994. Disponível em: https://doi.apa.org/doiLanding?doi=10.1037\%2F0033295X.101.3.371. Acesso em: 01 abr. 2019.

GRONLUND, N. E. A elaboração de testes de aproveitamento escolar. São Paulo: EPU, 1974.

KATO, M. A. O aprendizado da leitura. São Paulo: Martins Fontes, 2007.

KINTSCH, W. Comprehension: a paradigm for cognition. Cambridge: Cambridge University Press, 1998.

KOCH, I. V.; ELIAS, V. M. Ler e compreender os sentidos do texto. São Paulo: Contexto, 2011.

LEFFA, V. J. Aspectos da leitura: uma perspectiva psicolinguística. Porto Alegre: Sagra-Luzzatto, 1996.

MARCUSCHI, L. A. Produção textual, análise de gêneros e compreensão. São Paulo: Parábola, 2008. 
PEREIRA, V. W. Um estudo comparativo sobre o desempenho em compreensão leitora de alunos da educação básica. 2018. Relatório de pesquisa apresentado a FAPERGS, Porto Alegre, 2018.

PEREIRA, V. W. Predição leitora e inferência. In: COSTA, J. C (org.). Inferências linguísticas nas interfaces. Porto Alegre: EDIPUCRS, 2009. p.10-22.

PEREIRA, V.W. Compreensão leitora em alunos do Ensino Médio. ReVEL, [s. l.], v.6, n.11, p.1-15, 2008.

POERSCH, J. M. Por um nível metaplícito na construção do sentido textual. Letras de Hoje, Porto Alegre, v.26, n.4, p.127-143, 1991.

SCLIAR-CABRAL, L. Processamento da leitura: recentes avanços das neurociências. In: PEREIRA, V. W.; COSTA, J. C. (org.). Linguagem e cognição: relações interdisciplinares. Porto Alegre: EDIPUCRS, 2009. p.49-60.

SCLIAR-CABRAL, L. Processamento bottom-up na leitura. Revista de Estudos Linguísticos Veredas: Psicolinguística, Juiz de Fora, v.12, n.2, p.24-33, 2008. Disponível em: https:/www.ufjf.br/revistaveredas/files/2009/12/artigo02.pdf. Acesso em: 01 abr. 2019.

SMITH, F. Compreendendo a leitura: uma análise psicolinguística da leitura e do aprender a ler. Porto Alegre: Artes Médicas, 2003.

SMITH, F. Leitura significativa. Tradução de Beatriz Affonso Neves. Porto Alegre: Artmed, 1999.

SÖHNGEN, C. O procedimento "cloze". Letras de Hoje, Porto Alegre, v.37, p.6574, 2002. Disponível em: http://revistaseletronicas.pucrs.br/ojs/index.php/fale/article/ view/14174/9411. Acesso em: 15 maio 2018.

SPINILLO, A. G. A dimensão social, linguística e cognitiva da compreensão de textos: considerações teóricas e aplicadas. In: MOTA, M. P. da; SPINILLO, A. G. (org.). Compreensão de textos. São Paulo: Casa do Psicólogo, 2013. p.171-198.

SPINILLO, A. G.; ALMEIDA, D. D. Compreendendo textos narrativo e argumentativo: há diferenças? Arquivos Brasileiros de Psicologia, Rio de Janeiro, v.66, n.3, p.115-132, 2015. Disponível em: https://www.redalyc.org/pdf/2290/229035339010.pdf. Acesso em: 01 maio 2019.

TAYLOR, W. "Cloze procedure": a new tool for measuring reability. Journalism Quarterly, Urbana, v.30, 1953. Disponível em: https://www.gwern.net/docs/ psychology/writing/1953-taylor.pdf. Acesso em: 19 maio 2019.

TINKELMAN, S. N. Melhorando os testes na sala de aula: um manual de procedimento na elaboração de testes para os professores. Rio de Janeiro: USAID, 1967. 
VIANNA, H. M. Testes em Educação. São Paulo: IBRASA, 1982

VIDAL-ABARCA, E.; RICO, G. M. Por que os textos são tão difíceis de compreender? as inferências são a resposta. In: TEBEROSKY, A. (org.). Compreensão da leitura: a língua como procedimento. Porto Alegre: Artmed, 2003. p.139-153.

Recebido em 10 de abril de 2020

Aprovado em 1 de abril de 2021 